\title{
Efeito do Tamoxifeno na Expressão do Antígeno Nuclear de Proliferação Celular (PCNA) no Epitélio e no Estroma do Fibroadenoma de Mulheres no Menacme
}

Autor: Júlio Roberto de M. Bernardes Jr.

Orientador: Prof. Dr. Luiz Henrique Gebrim

Tese de Doutorado apresentada à Universidade Federal de São Paulo - Escola Paulista de Medicina - São Paulo, em 13 de abril de 2000.

O tamoxifeno vem sendo utilizado há quase três décadas no tratamento adjuvante do câncer de mama, sendo também eficaz na quimioprofilaxia desta doença e no controle da mastalgia cíclica. Sendo o fibroadenoma uma neoplasia benigna hormonodependente, com niveis de receptores estrogênicos mais altos que no lóbulo mamário, propôs-se avaliar o efeito deste fármaco na atividade proliferativa do epitélio e do estroma do fibroadenoma de mulheres no menacme, após tomarem-no, nas doses 10 e $20 \mathrm{mg} /$ dia, por 22 dias. Estudaram-se, de forma aleatória em duplo-cego, 40 mulheres eumenorréicas com fibroadenoma, que não receberam hormônios nem estiveram grávidas nos últimos 12 meses. As pacientes foram divididas em três grupos: A ( $\mathrm{n}=14$; placebo), B ( $\mathrm{n}=13 ; 10 \mathrm{mg} /$ dia) e C ( $\mathrm{n}=13 ; 20 \mathrm{mg} /$ dia). Iniciou-se o tratamento no $1^{\circ}$ dia do ciclo menstrual, e as cirurgias foram no $22^{\circ}$. Realizaram-se duas dosagens do estradiol, da progesterona e da globulina carreadora de hormônios esteroídicos (SHBG), sendo a primeira no $22^{\circ}$ dia do ciclo anterior e a segunda no dia da cirurgia. O tecido mamário foi fixado em formol a $10 \%$, corado pela $\mathrm{HE}$ e, posteriormente, processado para reação imuno-histoquímica ( $\mathrm{PC}-10$ Dako code $\mathrm{n}^{\circ} \mathrm{M} 879$ Denmark A/S). Avaliou-se a imunoexpressão do antígeno nuclear de proliferação celular (PCNA) no nú- cleo de, no mínimo, 500 células epiteliais e 500 estromais, contadas de forma interativa a partir do sistema computadorizado de análise digital Kontron Imaging System KS-300, com aumento de 400X. No tocante a positividade do PCNA no epitélio dos fibroadenomas, a porcentagem média de núcleos corados nos grupos A, B e C foi, respectivamente, de 25,2; 19,3 e 18. Contudo, a análise de variância destes dados não registrou diferença significante $(p=0,168)$. No estroma dos fibroadenomas, a porcentagem média de núcleos corados no grupo A foi 32,4 ; no grupo B foi 23,2 e no grupo $\mathrm{C}$ foi 18,4 . A análise de variância $(p=0,031)$ e o teste de comparações múltiplas de Fisher (intervalo de confiança 1,$39 ; 26,67)$ confirmaram que o número de núcleos expressando o PCNA no estroma foi significantemente menor no grupo C (20 mg/dia) em relação ao grupo A (controle). No entanto, não houve diferença significante entre os grupos B (10 mg/dia) e C $(20 \mathrm{mg} / \mathrm{dia})$. Assim, concluiu-se que o tamoxifeno reduziu, após 22 dias de tratamento, a expressão do PCNA apenas no estroma do fibroadenoma, quando administrado na dose de $20 \mathrm{mg} /$ dia.

Palavras-chave: Fibroadenoma. Mama: doença benigna. Proliferação celular. Antiestrogênicos. SERMS.

\section{Estudo Comparativo de Sistemas de Graduação em Preparados Citológicos e Histológicos para Carcinoma Infiltrante de Ductos Mamários. Avaliação da Concordância Cito-Histológica}

\author{
Autora: Karla Adriana Nascimento Dantas \\ Orientadores: Prof. Dr. Osvaldo Giannotti Filho e Profa. Dra. Gilda da Cunha Santos
}

Tese apresentada à Universidade Federal de São Paulo - Escola Paulista de Medicina, para obtenção do Título de Mestre em Anatomia Patológica em 7 de abril 1999.

O grau histológico tem sido considerado um dos principais fatores prognósticos do carcinoma ductal invasivo da mama, correlacionando-se significativamente com a taxa de sobrevida livre de doença. Com o advento da quimio e radioterapia neoadjuvantes como tratamentos primários, tem-se procurado graduar os tumores nos aspirados citológicos, para evitar graduar espécimes cirúrgicos com alterações histológicas relacionadas à terapia. Alguns estudos têm mostrado que a graduação citológica nos aspirados de carcinoma de mama correlaciona-se bem com a graduação histológica, sen- do altamente reprodutível. A avaliação da concordância cito-histológica foi realizada em estudo retrospectivo de 50 casos de punção aspirativa por agulha fina de carcinoma ductal invasivo de mama, confirmados histologicamente, aplicando-se de forma comparativa cinco sistemas de graduação. As classificações foram separadas segundo critérios de graduação tumoral (critérios nucleares e arquiteturais - sistemas de Mouriquand e de Guilford) e nuclear (sistemas de Black modificado por Fisher-BM, de Black simplificado-BS e de Hunt). As classificações utilizadas na histologia fo- 
ram os sistemas de graduação de Scarff-BloomRichardson modificado por Elston (SBR modificado), para avaliação tumoral, e o de BM, para avaliação nuclear. Os sistemas de graduação citológica que apresentaram maior concordância foram os sistemas de $\mathrm{BM}$ e BS, baseados em critérios nucleares (anisonucleose, tamanho, mitose e cromatina). Dentre os sistemas de graduação citológica que apresentam critérios nucleares e arquiteturais (combinados), a classificação de Guilford demonstrou maior signifi- cância, possivelmente pelo número maior de variáveis utilizadas, possibilitando menor margem de erro.

Diante dos resultados demonstrados pela análise estatística, constatou-se que estes métodos, neste estudo, são considerados razoáveis como sistemas de graduação citológica.

Palavras-chave: Mama: câncer, diagnóstico. Punção aspirativa. Tumores: classificação.

\section{RBCO 22(7):462,2000}

Resumo de Tese

\section{Avaliação da Quantidade do Colágeno da Pele de Ratas Castradas após o Uso de Estrogênio, Progestagênio e Tamoxifeno}

Autor: Marcelo Alvarenga Calil

Orientador: Prof. Dr. Edmund Chada Baracat

Tese apresentada ao Curso de Pós-Graduação em Ginecologia do Departamento de Tocoginecologia da Universidade Federal de São Paulo - Escola Paulista de Medicina para obtenção do título de Mestre em Ginecologia, 29 de abril de 1999.

Avaliou-se, neste estudo, a quantidade de colágeno da derme de ratas adultas castradas e medicadas com estrogênio, progestagênio e tamoxifeno. Estudaramse 45 ratas adultas, castradas, que foram divididas em cinco grupos: Grupo I $(n=9)$ recebeu propilenoglicol (placebo); Grupo II $(\mathrm{n}=9)$ recebeu $250 \mathrm{mg} \mathrm{de}$ tamoxifeno; Grupo III $(\mathrm{n}=9)$ recebeu $50 \mathrm{mg}$ estrogênios conjugados eqüinos; Grupo IV $(\mathrm{n}=8)$ recebeu $2 \mathrm{mg}$ de acetato de medroxiprogesterona; Grupo V $(n=10)$ recebeu $50 \mathrm{mg}$ de estrogênios conjugados eqüinos e 2 mg de acetato de medroxiprogesterona. Os fármacos foram diluídos em 0,5 ml de propilenoglicol e administrados diariamente, por gavagem, durante 60 dias. Após este periodo, os animais foram sacrificados e retiraram-se fragmentos de pele do dorso, para o estudo histomorfométrico pelo sistema de análise digital de imagem por computador (Imagelab - Softium). Observou-se aumento estatisticamente significante na quantidade de colágeno na derme dos animais que receberam tamoxifeno, estrogênios eqüinos conjugados e acetato de medroxiprogesterona isolados ou associados (grupos II, III, IV e V), em comparação com o grupo controle ( I ). Concluiu-se que a terapêutica com estrogênios e/ou progestagênios, isolados ou associados, bem como o uso de tamoxifeno, promoveu aumento significante na quantidade de colágeno da derme de ratas adultas castradas.

Palavras-Chave: Terapia de reposição hormonal. Colágeno. 